\title{
The Political Economy of Efficient Public Good Provision: Evidence from Flemish Libraries using a Generalised Conditional Efficiency Framework
}

\author{
Kristof De Witte* $\quad$ Benny Geys ${ }^{\dagger}$
}

June 3, 2009

\begin{abstract}
Provision of most public goods (e.g., health care, library services, education, utilities) can be characterised by a two-stage 'production' process. The first stage translates basic inputs (e.g., labour and capital) into service potential (e.g., opening hours), while the second stage describes how these programmatic inputs are transformed into observed outputs (e.g., school outcomes, library circulation). While the latter stage is best analysed in a supply-demand framework, particularly in the former stage one would like to have efficient public production. Hence, unlike previous work on public sector efficiency (which often conflates both 'production' stages), this paper analyses how political economy factors shape efficient public good provision in stage one (using local public libraries as our centre of attention). To do so, we use a specially tailored, fully non-parametric efficiency model. The model is rooted in popular Data Envelopment Analysis models, but allows for both outlying observations and heterogeneity (i.e., a conditional efficiency model). Using an exceptionally rich dataset comprising all 290 Flemish public libraries, our findings suggest that the ideological stance of the local government, the wealth and density of the local population and the source of library funding (i.e., local funding versus intergovernmental transfers) are crucial determinants of library efficiency.
\end{abstract}

Keywords: Nonparametric estimation, Conditional efficiency, Political economy, Public good provision, Libraries.

JEL-classification: C14, C61, I21

\footnotetext{
${ }^{*}$ Centre for Economic Studies, University of Leuven (KU Leuven), Naamsestraat 69, 3000 Leuven, Belgium, phone: 003216326 850, kristof.dewitte@econ.kuleuven.be; and Top institute for Evidence Based Education Research, Maastricht University, Kapoenstraat 23, 6200 MD Maastricht, the Netherlands, phone: 003143388 3750, k.dewitte@maastrichtuniversity.nl.

†Wissenschaftszentrum Berlin für Sozialforschung, Reichpietschufer 50, D-10785 Berlin, Germany, phone: 004930254 91415, geys@wzb.eu.
} 


\section{Introduction}

Economic efficiency - understood in terms of providing a maximum amount of output for a given level of inputs (e.g., Koopmans, 1951; Fried et al., 2008) - is often considered an important requirement for private firms. Minimizing inefficiency increases the performance and profitability of firms and, thus, benefits shareholders. In recent years, increasing attention has also been paid to efficiency requirements in the public sector (e.g., Lindblad, 2006). The reason is that, while needs are high, "budget constraints ensure that there is only so much money available" (Chen, 1997, 71). ${ }^{1}$ The strongly increased importance of efficiency in the public sector leads to the question what determines efficient public good provision. Why are some jurisdictions or public service providers able to offer more (or better) services than others using an equal amount of inputs?

We are clearly not the first to study public sector efficiency (see De Borger and Kerstens, 2000 , for a review). Numerous studies have previously taken up this issue both with respect to particular areas of public good provision (e.g., waste collection, police services, road maintenance, and so on; see Kalseth and Ratts $\varnothing$, 1998; De Borger and Kerstens, 2000) and general assessments of public performance (e.g., Vanden Eeckaut et al., 1993; De Borger et al., 1994; Geys, 2006; Balaguer-Coll et al., 2007; Borge et al., 2008; Geys et al., 2008). Nonetheless, we differ from previous work in three important respects.

First, we start from the view that many public services - such as health care, education, libraries - require active involvement by the recipient of the service in the delivery of this service. For example, demand for library services to a large extent drives the observable 'output' of libraries - in terms of circulation of books or audiovisual materials, and in-house use of materials. As a result, "the amount of service delivered is, to some extent, beyond the control of the provider" (Hammond, 2002, 650). This, however, implies that the observable output (e.g., library circulation) cannot really be employed as an 'output' indicator in studies of productive efficiency, as it is in a strict sense not really 'produced' by the public service provider. In fact, this argument implies that public good provision can be characterised by a two-stage 'production' process (adapted from Hammond, 2002, 2005). In the first stage, basic inputs - such as (expenditures on) labour and capital - are employed for producing "service potential" - such as collection size and opening hours (in the case of public libraries). In a second stage, these "programmatic inputs" (Vitaliano, 1998) are transformed into observable outputs - such as book circulation and request processing. Whereas most previous work ignores this specific nature of the public good production process and focuses on the second

\footnotetext{
${ }^{1}$ The existence of such efficiency requirement obviously does not imply that efficiency takes, or should take, precedence over other aims of public service provision. As in the private sector, efficiency should be viewed as one among many aims; including effectiveness, equity, responsiveness, adequateness and appropriateness (Dunn, 2004).
} 
stage, or analyses some hybrid of both stages (see Section 2 below), we explicitly focus on the first stage of this production process. In our view, this is a more appropriate environment for efficiency analysis because efficiency can here easily be understood as translating a given amount of public expenditures into a maximum possible amount of service potential (whereas the second stage is more appropriately analysed in a supply-demand framework).

As a second contribution, we employ a recently developed fully non-parametric framework. The non-parametric nature of the model derives from the difficulty - if not impossibility - to argue that the public good production process follows one or another functional form. Therefore, throughout the paper, we do not make any a priori assumption on the production technology. While our approach is in this respect closely related to Data Envelopment Analysis (DEA) models (Charnes et al., 1978; Deprins et al., 1984), it is more advanced than traditional DEA by allowing for outliers (following the order- $m$ technique of Cazals et al., 2002) and heterogeneity. We tackle the latter by using the conditional efficiency estimators of Daraio and Simar $(2005,2007)$. As the conditional efficiency estimates do not require a separability condition (i.e., the assumption that the exogenous environment does not influence the level of inputs and outputs), it is particularly convenient in the current application. The final model is based on De Witte and Kortelainen (2008), who extended Daraio and Simar $(2005,2007)$ to allow for (1) both discrete and continuous exogenous variables and (2) statistical inference in the conditional efficiency approach. As such, besides reducing the impact of outliers and controlling for heterogeneity, we are able to non-parametrically evaluate the influence of exogenous characteristics on the service potential of public good providers.

The latter constitutes our third contribution. Previous studies generally fail to evaluate how the institutional environment - in terms of socio-demographic, economic or political characteristics - affects efficiency, or look at this via a two-stage approach (e.g., Worthington, 1999; Hemmeter, 2006). Both exclusion from the model of such background factors and their use in a two-stage approach, however, lead to biased results and incorrect inferences (see Battese and Coelli, 1995; Stevens, 2004 and Kumbhakar et al., 1991; Reifschneider and Stevenson, 1991). In this paper, we include, using the above-mentioned non-parametric conditional efficiency model, the operational environment immediately in the efficiency estimates. We thereby concentrate on the following elements: (1) ideological stance of the local government, (2) share of women in the local council, (3) wealth of the municipality, (4) population concentration, and (5) source of public funding.

While our view on public good production as a two-stage production process is applicable to a wider range of public goods, our empirical application concentrates on local public libraries. We thereby exploit an exceptionally rich data set of all 290 Flemish public libraries in 2007. Studying Flemish public libraries is particularly attractive for our purpose since in Flanders political actors have significant influence on the day-to-day running of the 
library. Therefore, this creates a best-case scenario to evaluate the potential impact of political economy indicators. Our central findings suggest that the ideological stance of the local government, the wealth and density of the local population and the source of library funding (i.e., local funding versus intergovernmental transfers) are significant determinants of an efficient generation of 'service potential'. At odds with recent work on the effect of female representation (Pande, 2003; Chattopadhyay and Duflo, 2004; Geys and Revelli, 2009; Svaleryd, 2009), the number of women in the local government (or the presence of a female mayor) does not add to the explanatory power of the model, ceteris paribus.

The remainder of the paper is structured as follows. Section 2 reviews the foregoing literature on library efficiency estimation. Then, in Section 3, we describe the theoretical background and main hypotheses. Section 4 introduces the estimation methodology, while Section 5 presents the institutional setting and data employed in the present study. Our main findings are brought together in Section 6. Finally, the main conclusions are summarized in Section 7 .

\section{Literature review}

Libraries, whether run by local governments or universities, have a very specific and important task. They provide access to information. Usually, however, they have to manage this with a limited budget. These budgets have recently also shown a tendency to decrease rather than increase. This holds both for public and academic libraries (e.g., Shim and Kantor, 1998; Hammond, 2002). As a result, the measurement and determinants of library efficiency have received increasing attention in the literature. Two related, though distinct, approaches have thereby been employed. (1) In early work, scholars were predominantly interested in scale efficiency of libraries by analysing whether libraries are operating under increasing, constant or decreasing returns to scale (e.g., Goddard, 1973; Cooper, 1979; DeBoer, 1992; Hammond, 1999; Ikeuchi, 2001; Liu, 2003; for an early review, see Van House, 1984). The question addressed here is whether provision is taking place at an optimal scale of production, or whether there exists a possibly "substantial potential for a reduction in costs" by altering

the scale of provision (Hammond, 1999, 288). (2) Since the mid 1990s, scholars have taken a more general approach and started assessing whether libraries provide a maximum amount of output for a given level of inputs (e.g., Chen, 1997; Vitaliano, 1997, 1998; Shim and Kantor, 1998; Sharma et al., 1999; Worthington, 1999; Kao and Liu, 2000; Hammond, 2002, 2005; Shim, 2003; Kao and Lin, 2004; Chen et al., 2005; Hemmeter, 2006; Reichmann and Sommersguter-Reichmann, 2006; Liu and Chuang, 2009; for a review, see Shim, 2003).

Consider first the results of the scale economies approach. There initially appeared little consensus among researchers. While an early study on US public libraries by Goddard (1973) 
reveals the existence of economies of scale, Cooper (1979) demonstrates constant returns to scale in US library production and Feldstein (1976) even finds significant diseconomies of scale (though this study excluded small libraries). These contrasting findings led Van House (1984) to conclude that evidence is, at best, ambiguous. More recent results, however, using more advanced methodologies, converge towards increasing rather than decreasing returns to scale in library service provision. For example, DeBoer (1992) - analysing 194 Indiana public libraries in 1988 - finds that scale economies exist for small libraries, while larger ones exhibit constant returns to scale. He thereby suggests that Feldstein's (1976) diverging findings may have been driven by the exclusion of small libraries. Hammond (1999), replicating DeBoer (1992) for 152 UK public library systems in 1995/96 and extending it by considering multiple outputs, likewise finds significant increasing returns to scale in library services. ${ }^{2}$ Finally, analyzing 89 US academic research libraries in 1999/2000, Liu (2003) also concludes that economies of scale exist.

While providing one means to assess whether libraries are working at an optimal scale, the 'scale economies' approach does not allow assessing the overall productive (or technical) efficiency of libraries. That is, one cannot assess whether inputs are used in the best possible way. The latter question has been the subject of a second group of studies starting off with the doctoral research of Easun (1992) and reviewed in Shim (2003). While a large variety of countries, settings (i.e., public, university and school libraries) and definitions of libraries' inputs and outputs have been employed, most studies have relied on Data Envelopment Analysis (DEA) as their main statistical tool (the only three exceptions being Vitaliano, 1997; Hammond, 2005 and Hemmeter, 2006). While all studies find significant inefficiencies, little consensus exists as to what causes these inefficiencies. ${ }^{3}$ Vitaliano (1998) - using a sample of 184 public libraries in New York - shows efficiency is higher in larger cities and that excessive opening hours are the main cause of observed inefficiencies. Hammond (2002) - looking at 99 multi-outlet UK public library systems in 1995/96 - does not find any effect of excessive opening hours, but rather attributes inefficiency to oversubscription to periodicals. Likewise, while Vitaliano (1997) - for a sample of 235 libraries (including branches) in New York shows that non-profit libraries are more efficient than government-run ones, Hemmeter (2006) contradicts this findings in an analysis of 3308 US library systems over the period 1994-2001. Interestingly, however, the latter study also illustrates that a larger share of library income coming from local sources increases efficiency (especially for small libraries), suggesting that "local government can play an important monitoring role among public libraries" (Hemmeter,

\footnotetext{
${ }^{2}$ Interestingly, cost complementarities among the various library outputs (i.e. economies of scope) appear to be absent.

${ }^{3}$ Whereas the remaining discussion revolves around public libraries, studies on university and academic research libraries include Chen (1997), Shim and Kantor (1998), Kao and Liu (2000), Shim (2003), Kao and Lin (2004), Reichmann and Sommersguter-Reichmann (2006) and Liu and Chuang (2009).
} 
$2006,345)$.

In our view, two important problems confront this large literature. First, most of these studies fail to control for non-discretionary factors affecting library efficiency, or look at this via a two-stage approach (e.g., Worthington, 1999; Hemmeter, 2006). As mentioned above, both lead to biased results and incorrect inferences. Given the crucial importance to incorporate controls for exogenous factors in the analysis, we exploit a novel non-parametric approach that allows incorporating the operational environment immediately in the efficiency estimates. Second, all the above-mentioned studies tend to rely on observable outputs (most often library circulation data) as their output measure. As argued above - and returned to more extensively below - this cannot really be employed as an 'output' indicator in studies of productive efficiency, as it is not really 'produced' in a strict sense by the public service provider. That is, observed output is to some extent beyond the control of the provider since it is also affected by public demand. Our analysis starts from a clear view of the public good production function, and concentrates on that part of the 'production' process where the public service provider has full control over the transformation of inputs into outputs (defined in more detail below).

\section{Theoretical background and hypotheses}

Essentially, we view the public good production process as being characterised by a twostage 'production' process (adapted from Hammond, 2002, 2005). In a first stage, basic inputs - such as (expenditures on) labour and capital - are employed in the production of what could be described as 'service potential' (Bookstein, 1981; Hammond, 2002). For public libraries (the focus of our empirical analysis below), one can think of collection size and opening hours. ${ }^{4}$ In the second stage, these 'programmatic inputs' (cf. Vitaliano, 1998) are then transformed into observable outputs (such as book circulation and request processing). Clearly, however, the finally observed amount of public service 'output' from this second stage depends on an active involvement by the recipient of the service in its delivery. That is, the 'outcome' of the latter stage is not solely determined by the public service provider, but also depends to an important extent on the demand that lives in a given area for the services provided. Recognizing this is crucially important when evaluating the efficiency of public service provision.

In evaluating efficient public good provision, our analysis below concentrates on the first stage of the above-described production process for two related reasons. Firstly, this stage is the most appropriate environment for efficiency analysis. Specifically, as the second stage

\footnotetext{
${ }^{4}$ While we focus on library efficiency in the analysis, the same argumentation can be made for other types of public services (e.g., education, health care, water services, waste collection).
} 
of the production process relies at least in part on demand for public services, incorporating it into the efficiency analysis can lead to strongly biased inferences. For example, when observed library circulation (i.e., the final 'output') is low, a relatively high-cost library will appear very inefficient when using circulation as the output variable in the analysis. Yet, it may at the same time be very efficient in translating its basic inputs into service potential. If so, using circulation as an output measure will lead it to be unduly punished simply because it suffers from low demand in its area. ${ }^{5}$ Focussing on the first stage of the public production process avoids this bias. Secondly, and more specific to the case of libraries studied here, it might be argued that libraries are not there to maximize circulation of books, but rather to maximize access to the reading materials and information sources it contains. In such understanding of the prime task of libraries, library efficiency relates to maximization of 'service potential', given the budget constraint, rather than library circulation (i.e., the first stage of the above-described production process).

Crucially, the extent to which this aim is achieved depends on the institutional (i.e., political, socio-demographic as well as financial) environment in which public service providers (in this case, public libraries) operate. Firstly, the political environment could matter because (1) right-wing parties and (2) male politicians might have different priorities in running a local library compared to, respectively, left-wing governments and female politicians. This prediction follows from a large political economy literature stating that ideology determines politicians' policy preferences (e.g., Hibbs, 1977; Tavares, 2004), as well as from more recent evidence indicating that gender is an important indicator of policy preferences (e.g., Lott and Kenny, 1999; Edlund and Pande, 2002; Funk and Gathmann, 2008) and determines policy outcomes (e.g., Pande, 2003; Chattopadhyay and Duflo, 2004; Geys and Revelli, 2009; Svaleryd, 2009). Specifically, this literature suggests that the latter groups - i.e. left-wing and female politicians - tend to be more egalitarian and socially conscious. Translated to the present setting, this implies that left-wing and female politicians might be more inclined to focus on the 'non-economic' benefits of libraries (supplying the opportunity to read for the less well-off, getting the population to read more extensively, and so on), thereby putting more pressure on local public libraries to maximize their service potential (given the limited budget). ${ }^{6}$ The political environment may be particularly important in our setting (i.e., Flanders). Indeed, political actors have significant influence on the day-to-day running of the library since opening hours, budgets, staffing, and so on all need to be approved by the

\footnotetext{
${ }^{5}$ This is not to say that high-cost libraries should be placed in low-demand areas. Clearly, this would be a waste of public resources. Rather, the argument is that, from a purely efficiency perspective, this library should be recognized as being efficient - and not be punished for an element beyond its control (i.e., public demand for its service).

${ }^{6}$ Clearly, they might also wish to increase the budget, but the crucial point here is that, for a given budget, they are more likely to push for higher service potential.
} 
local council. This yields a first hypothesis:

H1: Library efficiency is higher when a) the ideological stance of the local government is left-wing and b) the share of women in the local council is higher.

The municipal socio-demographic make-up is likely to affect library efficiency through its influence on the demand and willingness to pay for cultural goods. Indeed, demand and willingness to pay for such goods generally rise with income (e.g., Pommerehne, 1982; Throsby, 1994; Schulze and Ursprung, 1998; Getzner, 2004), such that high-income residents "may constitute a special interest group striving for cultural provisions" (Werck et al., 2008, 47; cf. Mueller and Murrell, 1986). They may therefore pressure local public libraries to maximize their service potential given the budgetary constraints. Related, distance is often argued to play a crucial role in deciding whether or not to visit a cultural event (see, e.g., Verhoeff, 1992; Bille Hansen, 1997; Boter et al., 2005; De Graaff et al., 2007). High concentration of population, by reducing the average cost of travelling to the library, thus increases the group of potential users of the library's services. As such, for a given population size, urban areas (which are more densely populated) may have a larger share of its population interested in and striving for the efficient provision of cultural goods (in this case, library services). Moreover, lower travel costs can be argued to increase the 'option value' of library services. ${ }^{7}$ This leads to our second hypothesis:

H2: Library efficiency is higher in a) wealthier and b) densely populated areas.

Finally, we know from standard principal-agent theory (e.g., Alchian and Demsetz, 1972; Jensen and Meckling, 1976; Holmström, 1979; Laffont and Tirole, 1986) that monitoring is likely to reduce information asymmetries between principal and agent. Indeed, this literature shows that under perfect monitoring a first-best solution can still be reached. In other words, there is a strong disciplining effect of monitoring that - by limiting possibilities for wasteful spending and rent extraction by the agent - is strictly welfare-improving (Alchian and Demsetz, 1972; Jensen and Meckling, 1976; Holmström, 1979; Frey, 1993). ${ }^{8}$ Monitoring, however, is likely to be higher when a larger share of library spending derives from local sources (i.e., fees and municipal subsidies) rather than subsidies from higher-level governments. The reason lies in a form of fiscal illusion, whereby an imperfect mapping of consumers and financiers of library services reduces the incentive to act as efficiency guards. It is, after all, other people's money that is being wasted. Applying this line of argument to our setting, libraries

\footnotetext{
${ }^{7}$ This follows from applying standard option pricing theory. Specifically, a decrease in the 'strike price' of an option (e.g., through lower travel costs) to acquire a given underlying commodity (i.e., library services) increases its value.

${ }^{8}$ Recent experimental evidence is generally supportive of such a disciplining effect of monitoring (e.g., Nagin et al., 2002; Dickinson and Villeval, 2008).
} 
are "more likely to value the careful use of public money when it originates mainly from own revenue sources rather than external transfers" (Geys et al., 2008, 3). This gives our third and final hypothesis (cf. Hemmeter, 2006):

H3: Library efficiency is higher when resources derive to a larger extent from own revenues.

\section{Empirical methodology}

To estimate efficiency in the first stage of the library production process and to determine its politico-economy influences (which are in the remainder considered as exogenous from the library's point of view), we could in principle employ several modelling techniques. However, a closer look at the data and hypotheses limits the possibilities. First, we should focus on a non-parametric model as there is no a priori information on the appropriate production technology for public services (e.g., libraries). In other words, we have no reason to believe that the relationship between the inputs, outputs and exogenous characteristics follows a specific functional form (e.g., Cobb-Douglas, Translog, Fourier, ...). Although non-parametric models have a lower rate of convergence, they have been shown to be more consistent compared to wrongly specified parametric models (Kneip et al., 1998). Second, as we have no information on price variables, we have to rely on a branch of non-parametric models particularly designed for public performance analysis: Data Envelopment Analysis (DEA; Charnes et al., 1978) and Free Disposal Hull (FDH; Deprins et al., 1984). Finally, given that we want to control for heterogeneity and test for the influence of the exogenous environment on library efficiency, the choice of modelling techniques is further narrowed to conditional efficiency estimators (Daraio and Simar, 2005, 2007) and, in particular, conditional efficiency models that allow for discrete and continuous exogenous variables (De Witte and Kortelainen, 2008).

The model starts from the set $\chi_{n}$ of observed combinations of inputs $x\left(x \in \mathbb{R}_{+}^{p}\right)$ and outputs $y\left(y \in \mathbb{R}_{+}^{q}\right)$. The set of all feasible input-output combinations defines the production technology: $\Psi=\left\{(x, y) \in \mathbb{R}_{+}^{p+q} \mid x\right.$ can produce $\left.y\right\}$. To determine the efficiency of the evaluated libraries, we start from the best practice observations, i.e., the libraries that are using the least inputs $x$ for a given amount of outputs $y$ (this is the so-called input-orientation; for alternative orientations, see Fried et al., 2008). These best practice observations constitute the best practice frontier, i.e., the border of the production technology $\Psi$. The inefficiency $\theta$ of the evaluated entity $(x, y)$ is estimated as the distance to the best practice frontier:

$$
\theta(x, y)=\inf \{\theta \mid(\theta x, y) \in \Psi\}
$$

where the input efficiency measure $\theta(x, y) \leq 1$ is the proportionate decrease of inputs, which the library operating at level $(x, y)$ should attain in order to be considered 'efficient' (i.e., $\theta(x, y)=1)$. 
Two options now arise. One could impose convexity on the production possibilities (as in DEA) or not (as in FDH). Not imposing convexity clearly implies a more general approach. Moreover, there are "no valid theoretical arguments for assuming a priori that production possibilities are truly convex" (Cherchye et al., 2000, 263-264) and some empirical studies suggest violations of the convexity hypothesis (e.g., Hasenkamp, 1976). Hence, as there is no clear justification in our application to estimate a convex hull around the data, we concentrate on the FDH model. The FDH model estimates the production possibility set as:

$$
\hat{\Psi}_{F D H}=\left\{(x, y) \in \mathbb{R}_{+}^{p+q} \mid y \leq y_{i}, x \geq x_{i},\left(x_{i}, y_{i}\right) \in \chi_{n}\right\}
$$

The FDH estimator for the Farrell input-oriented efficiency score is obtained by replacing $\Psi$ with $\hat{\Psi}$ in equation (1).

However, a major disadvantage of the traditional non-parametric FDH model is that all $n$ observations in the sample $\chi_{n}$ are considered to be potential best practices: $\operatorname{Prob}((x, y)$ $\epsilon \Psi)=1$. Therefore, atypical observations (e.g., due to measurement errors, very atypical structure of the entity, etc.) heavily influence the best practice frontier and, as a direct result, the efficiency scores. To reduce the influence of these atypical observations, we follow Cazals et al. (2002) in estimating the FDH efficiency of equation (1) relative to a partial frontier constituting of $m<n$ observations. By repeatedly drawing ( $B$ times) with replacement a subset of $m$ observations among those $x_{i}$ such that $y_{i} \geq y$ and averaging the efficiency scores relative to these $B$ subsets, we obtain a robust efficiency estimate $\theta^{m}(x, y)$. The robust estimates $\theta^{m}(x, y)$ are no longer bounded by 1 as the evaluated observation is not always included in the reference set. These 'super-efficient' efficiency scores (i.e., if $\theta^{m}(x, y)<1$ ) indicate that the observation is using less inputs than the average $m$ evaluated observations in its reference set. As such, the super-efficient observation is doing better than what would be expected. ${ }^{9}$

The robust efficiency approach of Cazals et al. (2002) proves extremely convenient to incorporate the exogenous environment. Traditional non-parametric models suffer from a separability condition in that the operational environment is assumed not to influence the inputs and outputs. However, in real life applications, this is clearly unrealistic. The conditional efficiency approach, developed by Cazals et al. (2002) and Daraio and Simar (2005, 2007), allows to incorporate the exogenous environment. Basically, while using the robust efficiency model described above, the idea is to draw the subsample of size $m$ in such a way that similar observations have a higher probability of being drawn. Hence, the resulting 'conditional' efficiency estimates $\theta^{m}(x, y \mid z)$ compare like with likes. As the seminal contributions did not allow for multivariate analysis of both discrete and continuous exogenous variables, De Witte

\footnotetext{
${ }^{9}$ Following the literature (e.g., Daraio and Simar, 2007), we select the size of the partial frontier $m$ as the value of $m$ from which on the percentage of super-efficient observations in only decreasing marginally with $m$. In our application, this corresponds to $m=50$. (whereas $n=290$, see below).
} 
and Kortelainen (2008) extended the approach. Basically, their approach uses mixed (i.e., both discrete and continuous) Kernel smoothing around the exogenous variables such that for every observation the probability of being similar to the evaluated observation is known.

A second advantage of the De Witte and Kortelainen (2008) extension - crucial for our analysis - arises from the possibility for statistical inference concerning the influence of the exogenous variables. This extents the original contributions of Daraio and Simar (2005), which allowed for a graphical inference on the effect of exogenous variables (i.e., favorable or unfavorable), to estimating a non-parametric $p$-value (using an on bootstrapping based approach). Similar as in Daraio and Simar $(2005,2007)$, the procedure is implemented by estimating the effect of the exogenous variables on the ratio of the conditional $\theta^{m}(x, y \mid z)$ to the unconditional $\theta^{m}(x, y)$ efficiency. Indeed, if an exogenous variable has an unfavorable effect on performance, then $\theta^{m}(x, y \mid z)$ (i.e., efficiency when taking $z$ into account) will be larger than the unconditional efficiency $\theta^{m}(x, y)$ for large values of $z$ (compared to small values of $z$; see Daraio and Simar, 2007). Non-parametrically bootstrapping this non-parametric regression allows us to obtain statistical inference (in particular, $p$-values).

\section{$5 \quad$ Institutional setting and data}

We are able to exploit an exceptionally rich data set including information on all 290 local public libraries in Flanders in the year 2007. These data derive from the Department 'Social Development and Local Cultural Policy' (Afdeling Volksontwikkeling en Lokaal Cultuurbeleid) of the Flemish Regional government. They collect - and make publicly available - information on library revenues (e.g., subsidies and fees), expenditures (on personnel, infrastructure, library collection maintenance), collection size (e.g., books, CDs, DVDs, and so on) and operations (i.e., circulation, requests, public readings, and so on) since 1998. We employ the most recent data available (i.e., 2007) as a change in the data collection methodology in 2006 makes the resulting data imperfectly comparable across time. Data on opening hours are, unfortunately not centrally collected and have been brought together by contacting the libraries themselves.

Given that DEA-based approaches - as the one employed here - tend to be sensitive to the number of inputs and outputs included (inclusion of more inputs and outputs strongly increases the number of efficient observations), we opt for three input and four output variables measuring local public library service potential. As inputs, we use expenditures on (1) personnel, (2) operating expenditures (Opex; mainly maintenance of the collection) and

(3) infrastructure. The 'basic' inputs are used to provide (1) youth books, (2) fiction and non-fiction books and (3) other media (cd, dvd, vhs, cd-rom) during a given number of hours per week. Hence, we use these three collection-related variables as indicators of library ser- 
vice potential. As a fourth output, we also include the total number of opening hours per week, as this proxies the actual accessibility of the library collection for potential borrowers. Descriptive statistics of the employed variables are presented in Table 1.

Table 1: Descriptive statistics for 2007

\begin{tabular}{lrrrr}
\hline \hline & Average & St. Dev & Min & Max \\
\hline Inputs & & & & \\
$\quad$ Personnel & 366539 & 474973 & 52914 & 4698859 \\
Opex & 70725 & 80184 & 5897 & 609432 \\
$\quad$ Infrastructure & 66827 & 217529 & 103 & 1794090 \\
\hline Outputs & & & & \\
Opening hours & 24 & 10 & 10 & 51 \\
Youth books & 25120 & 20800 & 4602 & 161986 \\
Fiction and non-fiction books & 40852 & 38909 & 6806 & 285218 \\
Media & 33455 & 59187 & 0 & 523144 \\
\hline Operational environment & & & & \\
Female mayor & 0.093 & 0.291 & 0 & 1 \\
ICG & 5.022 & 0.727 & 2.500 & 6.300 \\
Percentage female in council & 0.336 & 0.078 & 0.080 & 0.600 \\
Income & 12.930 & 1.390 & 9.547 & 17.536 \\
Population & 19780 & 20034 & 2337 & 235143 \\
Population density & 527 & 427 & 62 & 3053 \\
Subsidies Flanders & 0,833 & 0,102 & 0,165 & 0,979 \\
\hline \hline
\end{tabular}

As mentioned in Section 3, the exogenous institutional environment may heavily influence library performance, particularly in Flanders where the municipal council has significant influence on the daily management of the public library. To evaluate the three hypotheses derived in Section 3, we examine the effects of the (1) ideological stance of the local government, (2) share of women in the local council, (3) wealth of the municipality, (4) population concentration, and (5) source of public funding. These are measured as follows:

Firstly, we measure the Ideological Complexion of the local Government (ICG) as $I C G=$ $\sum_{i=1}^{n}\left(p_{i}\right.$.Complexion $\left.{ }_{i}\right)$, where $p_{i}$ is the seat share of party $i$ in the College of Mayor and Aldermen (i.e., the local government) and 'Complexion' refers to the ideological position of this party on a Left-Right scale (from 0 to 10). The data concerning a party's ideological position were obtained from Rihoux (2001) and are based on a self-placement survey asking presidents and spokesmen of the parties in the municipalities to locate their party on an ideological scale between 0 (Left) and 10 (Right). The figures range from 2.6 (Groen!) to 6.0 (Open VLD) (the extreme-right-wing party Vlaams Belang was not represented in any local 
government and is therefore not in the data set). As a higher ICG score represents more a right-wing government, we expect an unfavorable effect on efficiency.

Secondly, to measure the influence of female representation, we use two operationalisations. The first measures female representation as the share of female members in the municipal council (the local parliament). The more women are elected into the council, the more likely it is that female preferences are translated into actual policies. The second operationalisation attempts to gather whether female preferences are more likely to come about when there is a female mayor. In this case, we define female representation using an indicator variable equal to 1 when the mayor is female, 0 otherwise. Following Hypothesis 1, we expect women to be a force in favour of library efficiency.

Thirdly, real taxable per capita income (in $€ 1000$ ) is included to assess whether efficiency is higher in wealthier municipalities (driven by the idea that the well-off may constitute a special-interest group). Population density (measured as inhabitants per $\mathrm{km}^{2}$ ) is taken up as a measure for the degree of urbanisation. Testing Hypothesis 2, we expect a favorable effect to efficiency from an increasing population density.

Finally, libraries are a heavily subsidized public service in Flanders. A large share of these subsidies derives from the Flemish Regional government. These constitute no less than $72 \%$ of total library revenues on average. The remaining income is provided by municipal subsidies (roughly $11 \%$ of the budget on average) and various alternative resources such as membership fees (3\%), borrowing fees (5\%) and fines (5\%). We include the share of regional subsidies in the total library budget to evaluate the third hypothesis, i.e. whether efficiency is higher (lower) when resources derive to a larger extent from own revenues (higher-level government subsidies).

\section{Results}

The results of the efficiency estimations are summarized in Table 2 . In column 1, we present the results when we do not account for the exogenous environment (i.e., 'unconditional' efficiency). We find an average efficiency score of 0.79. This indicates that, on average, Flemish local public libraries would have to decrease their inputs by approximately $21 \%$ in order to produce their outputs equally efficiently as the best practices. There is, however, a very large disparity in the performance across libraries, as can be seen from the sizeable

standard deviation around this average inefficiency. Moreover, some efficiency scores are significantly larger than 1 (i.e., $\theta^{m}(x, y)<1$ ). Hence, some observations can be viewed as super-efficient: they perform better than the average $m$ observations in their reference sample.

To examine Hypotheses 1 to 3, we develop five alternative conditional efficiency models. In 
a first model (referred to as Model 1), we examine the influence of ideological stance, share of female politicians in the local council, average income, and population concentration. Model 2 adds population size to this baseline model, in order to check whether the population concentration effect not merely derives from a larger population as such. Model 3 adds a dummy variable for female mayors to assess whether this ads an independent effect on public library efficiency, once controlling for overall female representation in the local council (as in Model 1). To test Hypothesis 3, we develop a fourth model which includes the percentage of regional subsidies in total library revenues, while controlling for the ideological preferences of the municipality (in Model 4) and average income (Model 5).

Once we account for the exogenous environment (i.e., conditional efficiency), our earlier conclusions change in two important ways (results summarized in columns 2 to 6 of Table 2 for Models 1 to 5). First, the average efficiency score no longer deviates from 1, suggesting that the average local public library in Flanders provides its service potential efficiently. Second, the standard deviation around this mean reduces significantly. This indicates that a large part of the variation in inefficiency, which was observed in the unconditional efficiency estimates, is due to failing to account for exogenous factors. Both findings thus strongly support the importance of accounting for exogenous factors when evaluating public sector efficiency.

These summarized results, however, do not allow us to evaluate Hypothesis 1-3. Rather than concentrating on the raw efficiency estimations, it is therefore more interesting to consider the influence of the political economy variables on the efficiency scores. We represent the full estimation results for all five conditional models in Table 3. Before discussing these results, recall that, in an input-oriented framework, a positive effect on the median indicates an unfavorable effect on efficiency, while a negative effect on the median indicates a favorable effect on efficiency. ${ }^{10}$

Our results provide strong evidence in line with the first part of our first hypothesis. That is, right wing councils are associated with a statistically significant reduction in public library efficiency, ceteris paribus. This finding is robust to all specifications, and suggests that leftwing governments are indeed more likely to care about maximising library service potential (under a given budget). The second half of our first hypothesis is not supported. That is, although the share of female representatives in the local council has a positive effect on median efficiency - in line with expectations - this fails to be statistically significant. A similar conclusion is reached when examining the influence of a female mayor on efficiency (Model 3). Female mayors are not associated with a significant increase in library performance, ceteris

\footnotetext{
${ }^{10}$ We consider the effect on the median, rather than the mean, as the former is less influenced by extreme values. Note also that, due to the structure of the non-parametric bootstrap, we only present whether the exogenous variable has a significant (un)favorable effect to efficiency. The marginal coefficient on the median is less meaningful (see De Witte and Kortelainen, 2008).
} 
paribus. ${ }^{11}$

We find strong support for Hypothesis 2. Municipalities with higher income and urbanisation levels (i.e., more densely populated) have better performing libraries. The latter effect is not driven by population size. Indeed, when including population size in the estimation (Model 2), this turns out to be insignificant, while the effect of population concentration remains unaffected.

Finally, our results confirm Hypothesis 3. Libraries turn out to have a higher service potential when library revenues derive to a larger extent from local resources (i.e., municipal subsidies, fees and fines). This confirms the idea that monitoring has a strong and positive effect on local public good provision, and that incentives for monitoring are undermined when a larger share of income derives from higher-level government subsidies. This supports Hemmeter's (2006) findings for a sample of 3308 US library systems (see Section 2). It also confirms recent findings by Geys et al. (2008), who show that involvement of voters in local public affairs (e.g., through turnout in elections) mainly enhances local government efficiency when local governments have higher fiscal autonomy. When a larger share of local revenues comes from intergovernmental subsidies, "the efficiency-enhancing effect of voter involvement" is significantly reduced (Geys et al., 2008, 1).

Table 2: Order-m efficiency score

\begin{tabular}{rr|rrrrr}
\hline \hline & $\begin{array}{r}\text { Unconditional } \\
\text { (robust FDH) }\end{array}$ & Model 1 & Model 2 & Model 3 & Model 4 & Model 5 \\
\hline Average & 0.7892 & 1.0507 & 0.9891 & 1.0078 & 1.1082 & 1.0096 \\
St. Dev. & 0.6575 & 0.1946 & 0.1294 & 0.1606 & 0.2394 & 0.2029 \\
Min & 0.1965 & 0.5315 & 0.4778 & 0.5061 & 0.5018 & 0.5019 \\
Max & 5.4843 & 2.4027 & 2.0493 & 2.4284 & 2.0760 & 2.0093 \\
\hline \hline
\end{tabular}

As an alternative to the bootstrapped $p$-values presented in Table 3, we can also present the results graphically. As these might be more easily accessible than the results in Table 3 , we plot the results from Model 5 in Figure 1. In particular, we follow Daraio and Simar $(2005,2007)$ by non-parametrically regressing the ratio of the conditional and unconditional efficiency measure $Q^{z}=\frac{\theta^{m}(x, y \mid z)}{\theta^{m}(x, y)}$ on environmental factor $z$. Given that we have a multivariate framework, we examine partial regression plots (Badin et al., 2008), where the evaluated variable (i.e., share of Regional subsidies in total library revenue) changes and the other variables are kept at a fixed value (i.e., their mean). The result clearly illustrates the negative

\footnotetext{
${ }^{11}$ One potential explanation for this non-finding might be that municipalities with high female representation also tend to have more left-wing governments (assuming women are more likely to run - and be elected - on left-wing party lists). This, however, does not appear to be supported by the data. Indeed, while we do find the expected negative correlation between ICG and fcouncil, this relation is weak $(\mathrm{r}=-0.1140 ; p=0.07)$.
} 
Table 3: Influence of the exogenous environment on service potential of libraries

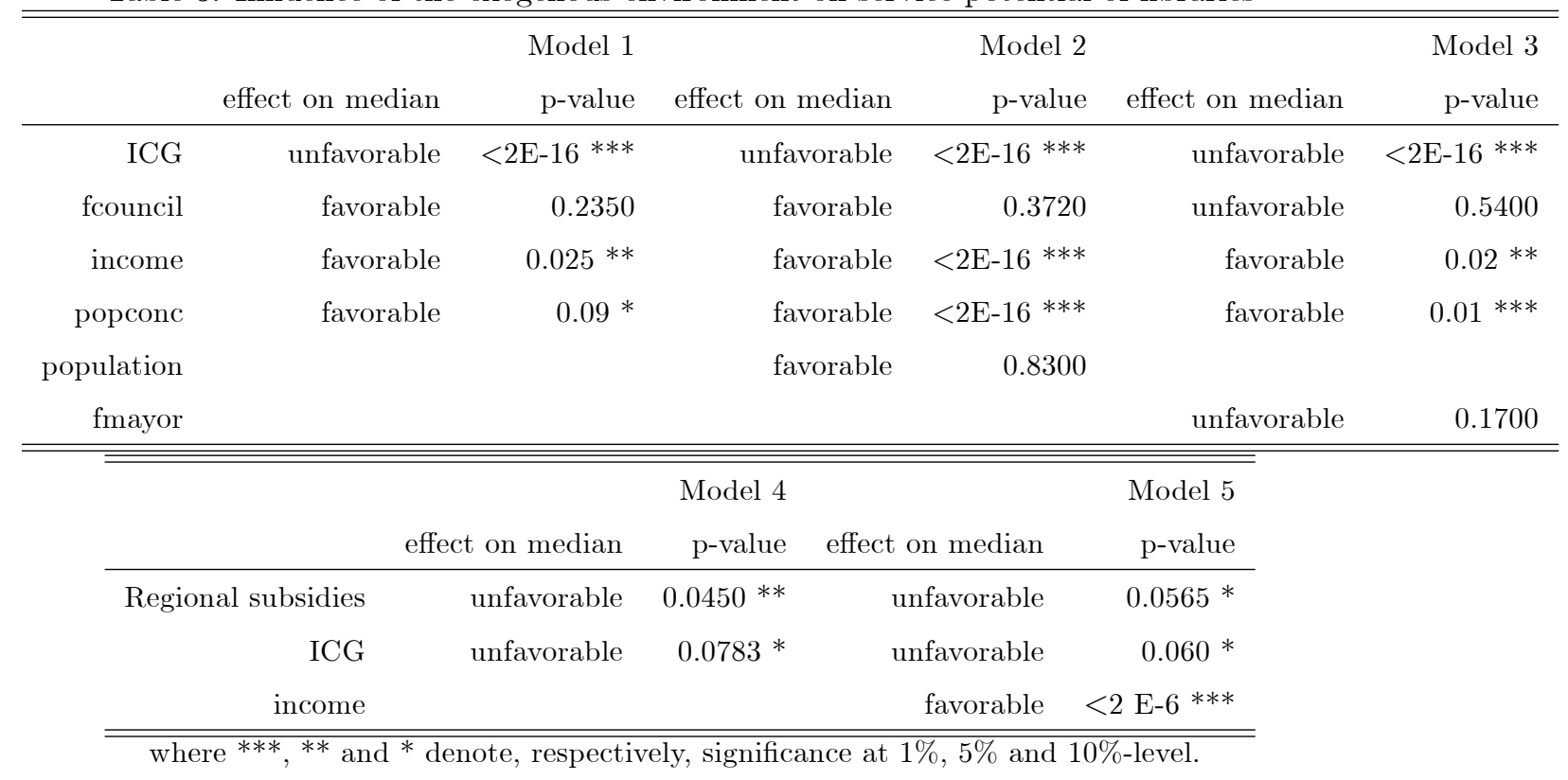

effect of a larger share of Flemish subsidies. When local public libraries rely to a larger extent on own resources, they are more efficient (service potential is higher for a given budget).

\section{Conclusion}

Economic efficiency - in terms of maximising output for a given level of inputs (e.g., Koopmans, 1951; Fried et al., 2008) - has become also an increasingly important element in public good provision (e.g., Lindblad, 2006). From an economist point of view, this easily leads to the question why some jurisdictions or public service providers are able to offer more (or better) services than others using an equal amount of inputs. We tackled this questions by focussing on three issues.

Firstly, we characterised public good provision as a two-stage 'production' process. A first stage translates basic inputs (e.g., labour and capital) into service potential (e.g., opening hours), while a second stage describes how these programmatic inputs are transformed into observed outputs (e.g., school outcomes, library circulation). While most previous studies do not consider this distinction in the production process, we consider the dichotomy as crucial for making accurate inferences in efficiency analyses. Indeed, the second stage outputs (e.g., library circulation, education outputs, health outcomes) are to a large extent beyond the control of the public service provider. Therefore, the second stage final outputs are inappropriate to evaluate efficiency of public good provision, and analyses should concentrate on the production of the first stage 'service potential' (which is fully under control of the 


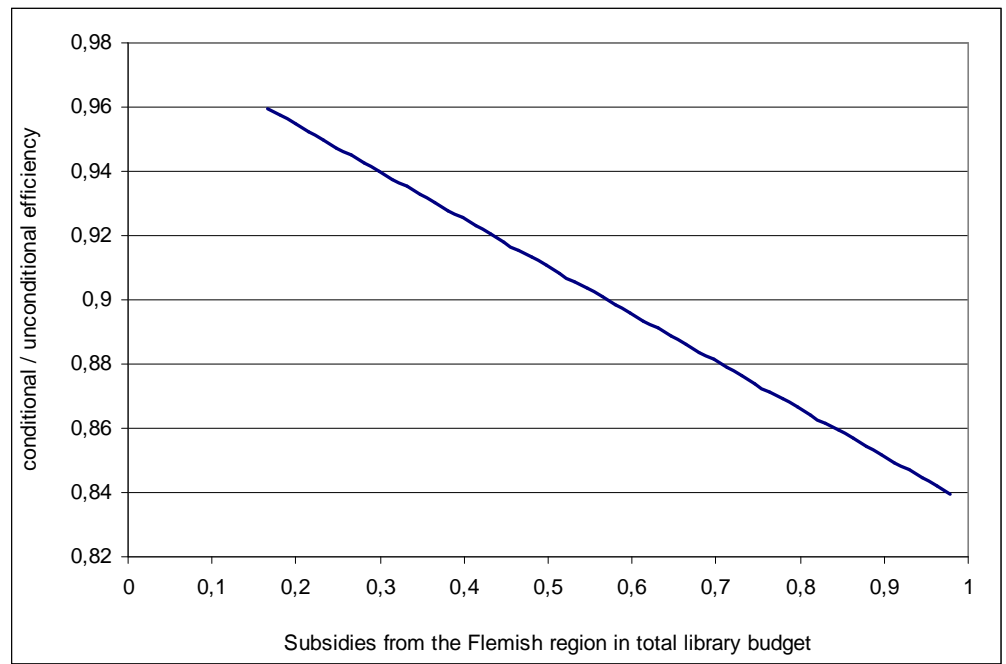

Figure 1: Partial regression plot of the effect of regional subsidies on efficiency

service provider).

Secondly, to examine efficiency in 'service potential', we explored a specially tailored and fully non-parametric framework, which is rooted in popular Data Envelopment Analysis (DEA) models (Charnes et al., 1978). By using a robust (i.e., allowing for outlying observations; Cazals et al., 2002) and conditional (i.e., allowing for heterogeneity; Daraio and Simar, 2005,2007; De Witte and Kortelainen, 2008) efficiency framework, we are able to evaluate non-parametrically (i.e., without any a priori assumption on the production function) how discrete and continuous exogenous variables affect observed efficiency. In addition, thanks to the conditional efficiency framework we can include the operational environment immediately in the efficiency estimates. Therefore, our approach does not rely on a separability condition, which inappropriately assumes that the exogenous environment does not have an impact on the inputs and outputs (Simar and Wilson, 2007).

Thirdly, using the previously described insights, this paper examines how political economy factors affect efficiency of local public good provision. We thereby focus on Flemish public libraries as in Flanders local political actors have a large influence on the day-to-day running of the library. The latter creates an attractive setting set to explore the influence of political economy factors on productive efficiency.

Our findings suggest that library efficiency (i.e., efficiency in the first stage of the public good production process) is higher when (1) the ideological stance of the local government is more left-wing, (2) the population is wealthier, (3) the area is more densely populated (i.e., the distance to the local library is smaller) and (4) the public service revenues derive to a larger extent from local resources. This confirms theoretical predictions that left-wing governments 
care more about maximising library service potential (under a given budget), interest groups are able to push towards higher efficiency and stricter monitoring (associated with higher reliance of local resources to fund libraries) increases efficiency. In addition, our results indicate that, ceteris paribus, (5) population size, (6) the share of female representatives in the local council, and (7) having a female mayor does not significantly affect library performances. The latter observation contrasts to recent work on the effects of female representation on public policy.

\section{References}

[1] Alchian, A.A. and H. Demsetz (1972). Production, Information Costs and Economic Organisation. American Economic Review 62, 777-795.

[2] Badin, L., C. Daraio and L. Simar (2008). Optimal Bandwidth Selection for Conditional Efficiency Measures: A Data-Driven Approach. Discussion Paper 0828, Institut de Statistique, UCL.

[3] Balaguer-Coll, M.T., E. Tortosa-Ausina and D. Prior (2007). On the Determinants of Local Government Performance: A Two-Stage Nonparametric Approach. European Economic Review 51 (2), 425-451.

[4] Battese, G.E. and T.J. Coelli (1995). A Model for Technical Efficiency Effects in a Stochastic Frontier Production Function with Panel Data. Empirical Economics 20, 325-332.

[5] Bille Hansen, T. (1997). The Willingness-to-pay for the Royal Theatre in Copenhagen as a Public Good. Journal of Cultural Economics 21, 1-28.

[6] Bookstein, A. (1981). An Economic Model of Library Service. Library Quarterly 51, 410-428.

[7] Borge, L.-E., T. Falch and P. Tovmo (2008). Public Sector Efficiency: The Impact of Political and Budgetary Institutions, Fiscal Capacity and Democratic Participation. Public Choice, 136, 475-495.

[8] Boter, J., J. Rouwendal and M. Wedel (2005). Employing Travel Time to Compare the Value of Competing Cultural Organizations. Journal of Cultural Economics 29 (1), 19-33.

[9] Cazals, C., J.P. Florens and L. Simar (2002). Nonparametric Frontier Estimation: A Robust Approach. Journal of Econometrics 106 (1), 1-25. 
[10] Charnes, A., W.W. Cooper and E. Rhodes (1978). Measuring Efficiency of DecisionMaking Units. European Journal of Operational Research 2 (6), 428-449.

[11] Chattopadhyay, R. and E. Duflo (2004). Women as Policy Makers: Evidence from a Randomized Policy Experiment in India. Econometrica 72 (5), 1409-1443.

[12] Chen, T.Y. (1997). Measurement of the Resource Utilization Efficiency of University Libraries. International Journal of Production Economics 53 (1), 71-80.

[13] Chen Y., H. Morita and J. Zhu (2005). Context-Dependent DEA with an Application to Tokyo Public Libraries. International Journal of Information Technology and Decision 4 (3), 385-394.

[14] Cherchye, L., T. Kuosmanen and T. Post (2000). What is the Economic Meaning of FDH? A Reply to Thrall. Journal of Productivity Analysis 13, 263-267.

[15] Cooper, M.D. (1979). The Economics of Library Size: A Preliminary Enquiry. Library Trends 28 (1), 63-78.

[16] Daraio, C. and L. Simar (2005). Introducing Environmental Variables in Nonparametric Frontier Models: A Probabilistic Approach. Journal of Productivity Analysis 24 (1), $93-121$.

[17] Daraio, C. and L. Simar (2007). Advanced robust and nonparametric methods in effciency analysis. Methodology and applications. Series: Studies in Productivity and Efficiency, Springer: Heidelberg.

[18] DeBoer, L. (1992). Economies of Scale and Input Substitution in Public Libraries. Journal of Urban Economics 32, 257-268.

[19] De Borger, B., K. Kerstens, W. Moesen and J. Vanneste (1994). Explaining Differences in Productive Efficiency: An Application to Belgian Municipalities. Public Choice 80, 339-358.

[20] De Borger, B. and K. Kerstens (2000). What is Known about Municipal Efficiency? The Belgian Case and Beyond, in J. Blank (ed.), Public Provision and Performance: Contributions from Efficiency and Productivity Measurement Elsevier: Amsterdam. pp. 299-330.

[21] De Graaff, T., J. Boter and J. Rouwendal (2007). On Spatial Differences in Attractiveness of Dutch Museums. Free University Amsterdam, mimeo.

[22] Deprins, D., L. Simar and H. Tulkens (1984). Measuring Labor Efficiency in Post Offices. In Marchand M., P. Pestieau and H. Tulkens (eds.), The Performance of Public Enterprises: Concepts and Measurements. North-Holland: Amsterdam. pp. 243-267. 
[23] De Witte, K. and M. Kortelainen (2008). Blaming the exogenous environment? Conditional efficiency estimation with continuous and discrete environmental variables. CES Discussion Paper Series DPS 08.33; MPRA Paper 14034.

[24] Dickinson, D. and M.-C. Villeval (2008). Does Monitoring Decrease Work Effort? The Complementarity between Agency and Crowding-Out Theories. Games and Economic Behavior 63, 56-76.

[25] Dunn, W.N. (2004). Public Policy Analysis: An Introduction. Pearson Prentice Hall: New Jersey.

[26] Easun, M.S. (1992). Identifying Efficiencies in Resource management: An Application of Data Envelopment Analysis to Selected School Libraries in California. Ph.D. Dissertation, University of California: Berkeley.

[27] Edlund, L. and R. Pande (2002). Why have Women Become Left-Wing? The Political Gender Gap and the Decline in Marriage. Quarterly Journal of Economics 117 (3), 917-961.

[28] Feldstein, K.F. (1976). The Economics of Public Libraries. Ph.D. Dissertation MIT: Boston.

[29] Frey, B.S. (1993). Does Monitoring Increase Work Effort? The Rivalry with Trust and Loyalty. Economic Enquiry 31, 663-670.

[30] Fried, H., C.A.K. Lovell and S. Schmidt (2008). The Measurement of Productive Efficiency and Productivity Growth. Oxford: Oxford University Press.

[31] Funk, P. and C. Gathmann (2008). Gender Gaps in Policy Making: Evidence from Direct Democracy in Switzerland, University of Pompeu Fabra, mimeo.

[32] Getzner, M. (2004). Exploring Voter Preferences in Cultural Policy: A Case Study for Austria. Empirica 31, 27-42.

[33] Geys, B. (2006). Looking across Borders: A Test of Spatial Policy Interdependence using Local Government Efficiency Ratings. Journal of Urban Economics 60 (3), 443-462.

[34] Geys, B., F. Heinemann and A. Kalb (2008). Voter Involvement, Fiscal Autonomy and Public Sector Efficiency: Evidence from German Municipalities. ZEW Discussion Paper 08-024.

[35] Geys, B. and F. Revelli (2009), Decentralization, Competition and the Local Tax Mix: Evidence from Flanders. University of Torino Working Paper nr.02/2009. 
[36] Goddard, H.C. (1973). Analysis of Social Production Functions: The Public Libraries. Public Finance Quarterly 1 (2), 191-204.

[37] Hammond, C.J. (1999). The Technology of Library Service Provision: A Cost Function Analysis of Public Library Systems in the United Kingdom. Information Economics and Policy 11, 271-295.

[38] Hammond, C.J. (2002). Efficiency in the Provision of Public Services: A Data Envelopment Analysis of UK Public Library Systems. Applied Economics 34 (5), 649-657.

[39] Hammond, C.J. (2005). Technical Efficiency and Organisational Change in UK Public Library Systems: A Stochastic Distance Function Approach. University of Hull Business School Research Memorandum 54.

[40] Hasenkamp, G. (1976). A Study of Multiple-Output Production Functions. Journal of Econometrics 4, 253-262.

[41] Hemmeter, J.A. (2006). Estimating Public Library Efficiency using Stochastic Frontiers. Public Finance Review 34 (3), 328-348.

[42] Hibbs, D. (1977). Political Parties and Macro-Economic Policy. American Political Science Review 71, 1467-1487.

[43] Holmström, B. (1979). Moral Hazard and Observability. Bell Journal of Economics 10 (1), 74-91.

[44] Ikeuchi, A. (2001). Empirical Study for Optimal Size of Public Libraries. Library and Information Science 46, 1-36.

[45] Jensen, M.C. and W.H. Meckling (1976). The Theory of the Firm: Managerial Behavior, Agency Costs and Ownership Structure. Journal of Financial Economics 3 (4), 305-360.

[46] Kalseth, J. and J. Rattsø (1998). Political Control of Administrative Spending: The Case of Local Governments in Norway. Economics and Politics. 10, 63-83.

[47] Kao, C. and S.T. Liu (2000). Data Envelopment Analysis with Missing Data: An Application to University Libraries in Taiwan. Journal of the Operational Research Society $51(8), 897-905$.

[48] Kao C. and Y.C. Lin (2004). Evaluation of the University Libraries in Taiwan: Total Measure versus Ratio Measure. Journal of the Operational Research Society 55 (12), $1256-1265$.

[49] Kneip, A., B. Park and L. Simar (1998). A note on the convergence of nonparametric DEA estimators for production efficiency scores. Econometric Theory 14, 783-793. 
[50] Kumbhakar, S.C., S. Gosh and J.T. McGuckin (1991). A Generalized Production Frontier Approach for estimating Determinants of Inefficiency in US Dairy Firms. Journal of Business and Economic Statistics 9 (3), 279-286.

[51] Koopmans, T.C. (1951). Activity Analysis of Production and Allocation. New York: John Wiley.

[52] Laffont, J.-J. and J. Tirole (1986). Using Cost Observation to Regulate Firms. Journal of Political Economy 94 (3), 614-641.

[53] Li, Q., and J.S. Racine (2007). Nonparametric Econometrics: Theory and Practice. Princeton: Princeton University Press.

[54] Lindblad, M.R. (2006). Performance Measurement in Local Economic Development. Urban Affairs Review 41 (5), 646-672.

[55] Liu, L.G. (2003). The Cost Function and Scale Economies in Academic Research Libraries. Library Trends 51 (3), 293-311.

[56] Liu, S.T. and M. Chuang (2009). Fuzzy Efficiency Measures in Fuzzy DEA/AR with Application to University Libraries. Expert Systems with Applications 36 (2), 1105-1113.

[57] Lott, J.R. and L.W. Kenny (1999). Did Women's Suffrage Change the Size and Scope of Government? Journal of Political Economy 107, 1163-1198.

[58] Mueller, D.C. and P. Murrell (1986). Interest Groups and the Size of Government. Public Choice 48, 125-146.

[59] Nagin, D.S., J.B. Rebitzer, S. Sanders and L.J. Taylor (2002). Monitoring, Motivation and Management: The Determinants of Opportunistic Behavior in a Field Experiment. American Economic Review 92 (4), 850-873.

[60] Pande, R. (2003). Can Mandated Political Representation Increase Policy Influence for Disadvantaged Minorities? Theory and Evidence from India. American Economic Review 93 (4), 1132-1151.

[61] Pommerehne, W.W. (1982). Steuern, Staatsausgaben und Stimmbürgerverhalten: Eine Empirische Untersuchung am Beispiel der Öffentlichen Subventionierung des Theaters. Jahrbucher für Nationalökonomie und Statistik 197 (5), 437-462.

[62] Reichmann G. and M. Sommersguter-Reichmann (2006). University Library Benchmarking: An International Comparison using DEA. International Journal of Production Economics 100 (1), 131-147. 
[63] Reifschneider, D. and R. Stevenson (1991). Systematic Departures from the Frontier: A Framework for the Analysis of Firm Inefficiency. International Economic Review 32 (3), 715-723.

[64] Schulze, G.G. and H.W. Ursprung (2000). La Donna e mobile - or is she? Voter Preferences and Public Support for the Performing Arts. Public Choice 102, 129-147.

[65] Sharma, K. R., P.S. Leung and L. Zane (1999). Performance Measurement of Hawaii State Public Libraries: An Application of Data Envelopment Analysis. Agricultural and Resource Economics Review 28, 190-198.

[66] Shim, W. (2003). Applying DEA Technique to Library Evaluation in Academic research Libraries. Library Trends 51 (3), 312-332.

[67] Shim, W. and P.B. Kantor (1998). A Novel Economic Approach to the Evaluation of Academic Research Libraries. Proceedings of information access in the global information economy 35, 400-410.

[68] Simar, L. and P. Wilson (2007). Estimation and inference in two-stage, semi-parametric models of production processes. Journal of econometrics 136 (1), 31-64.

[69] Stevens, P.A. (2004). Accounting for Background Variables in Stochastic Frontier Analysis. NIESR Discussion Paper 239.

[70] Svaleryd, H. (2009). Women's Representation and Public Spending. European Journal of Political Economy 25 (2), 186-198.

[71] Tavares, J. (2004). Does Right or Left Matter? Cabinets, Credibility and Fiscal Adjustments. Journal of Public Economics 88, 2447-2468.

[72] Throsby, C.D. (1994). The Production and Consumption of the Arts: A View of Cultural Economics. Journal of Economic Literature 32, 1-29.

[73] Vanden Eeckhaut, P., H. Tulkens, and M. Jamar (1993). Cost Efficiency in Belgian Municipalities. In H. Fried, C.A.K. Lovell and S. Schmidt (eds.) The Measurement of Productive Efficiency: Techniques and Applications. Oxford University Press: Oxford, pp. 300-334.

[74] Van House, N.A. (1984). Research on the Economics of Libraries. Library Trends 32, 407-423.

[75] Verhoeff, R. (1992). Explaining Differences in the Geographical Reach of Performances. Journal of Cultural Economics 16 (2), 73-82. 
[76] Vitaliano, D.F. (1997). X-Inefficiency in the Public Sector: The Case of Libraries. Public Finance Review 25, 629-643.

[77] Vitaliano, D.F. (1998). Assessing Public Library Efficiency using Data Envelopment Analysis. Annals of Public and Cooperative Economics 69 (1), 107-122.

[78] Werck, K., B. Heyndels and B. Geys (2008). The Impact of 'Central Places' on Spatial Spending Patterns: Evidence from Flemish Local Government Cultural Expenditures. Journal of Cultural Economics 32 (1), 35-58.

[79] Worthington, A. (1999). Performance Indicators and Efficiency Measurement in Public Libraries. Australian Economic Review 32 (1), 31-42. 